\title{
Os miseráveis de Victor Hugo: a invisibilidade através do nome ${ }^{1}$
}

\author{
Glória Gomide²
}

1 A primeira versão deste texto foi apresentada no seminário A visibilidade dos anônimos, promovido pelo Grupo de Pesquisa Mídia e Narrativa, da Pontifícia Universidade Católica de Minas Gerais (PUC-MG), em Belo Horizonte, nos dias 06 e 07 de novembro de 2013.

2 Professora Doutora na Faculdade de Comunicação e Artes da Pontifícia Universidade Católica de Minas Gerais (PUCMG). gloriagomide@gmail.com. 


\section{Resumo}

Palavras-chave

Os miseráveis de Victor Hugo, de 1862, é uma das obras mais adaptadas para outros suportes. Neste trabalho se quer demonstrar que a invisibilidade das personagens é paradoxalmente revelada pela mudança de seus nomes, os quais se transformam dependendo das oportunidades de se amalgamar na multidão. As alcunhas adotadas são apropriadas às situações dramáticas desenvolvidas na obra e nas adaptações, desde a arte sequencial a adaptações operísticas e cinematográficas. E se Os miseráveis é uma obra do século XIX, vê-se que, ainda hoje, é ecoada em personagens reais, que têm ceifadas suas vidas por causa de crimes primários e, ao contrário do anonimato, se escondem através de novas identidades na multidão contemporânea.

Literatura, cinema, adaptação, anonimato.

\section{Abstract}

Les misérables by Victor Hugo, written in 1862, is one of the literary works most adapted to other media. In this paper, our purpose is to show that the characters' invisibility is paradoxically revealed by changing their names, which are transformed depending on the opportunities of merging into the crowd. The nicknames adopted are suitable to dramatic situations developed in the book and in its adaptations from sequential art to operatic and cinematic adaptations. And even if Les misérables is a 19th century work, we understand that it still echoes in real characters, who have their lives claimed because of primary crimes and, unlike anonymity, they hide themselves behind new identities in the contemporary crowd.

\section{Keywords}

Literature, cinema, adaptation, anonymity. 
Victor Hugo pode ser considerado o precursor do Romantismo francês, escola que até então era de domínio anglo-germânico. O autor marca tal período com a publicação, em 1827, do drama em versos Cromwell, no qual contém seu famoso Prefácio, escrito sempre em maiúsculas, que lança os fundamentos do Romantismo na França.

Ali, Hugo lança um manifesto e faz uma análise da evolução da literatura em relação com a história até chegar a uma análise da sensibilidade moderna. Para alcançar o seu objetivo principal, Hugo realiza uma espécie de síntese em que filia as formas de arte poética a três momentos do desenvolvimento histórico da humanidade, ou melhor, a três idades do mundo: os tempos primitivos, de primeiros encantos com o mundo, que seriam líricos e teriam nas odes e nos hinos suas formas de expressão; os tempos antigos, em que já haveria grandes impérios e acontecimentos narrados em poemas épicos; e, por fim, os tempos modernos, que seriam dramáticos.

O longo Prefácio é a defesa do drama romântico, que, segundo Hugo, seria uma nova forma de poesia fruto dos tempos modernos que deveria superar por completo as velhas manifestações clássicas que se prendiam em demasia a regras fixas. Em síntese,

Os tempos primitivos são líricos, os tempos antigos são épicos e os tempos modernos são dramáticos. A ode canta a eternidade, a epopeia soleniza a história, o drama pinta a vida, o caráter da primeira poesia é a ingenuidade, o caráter da segunda é simplicidade, o caráter da terceira, a verdade (HUGO, 2007, p. 40).

No entanto, segundo Otto Maria Carpeaux, a obra de Hugo tem um lirismo que invade a eloquência, assim como a eloquência invade-lhe a poesia, abolindo todas as fronteiras entre os gêneros. Identifica também as influências estrangeiras em Hugo, mesmo em importância reduzida. Mostra que NotreDame de Paris tem um pouco de Walter Scott, com as pitadas de picaresco, mas é menos histórico e nos romances "sociais" o picaresco está ligado ao sentimentalismo, que descende de Rousseau (CARPEAUX, 2012, p. 1666). 
Assim, Os miseráveis é o maior romance "cinematográfico" (palavras de Carpeaux) que empolgou leitores, inclusive os chamados semicultos - no seu lançamento quase toda a classe operária francesa o leu. Desde então, emociona milhões com as grandes cenas épicas e abuso de generosidade ou maldade das personagens, fazendo com que o autor muitas vezes pareça ser ingênuo. Tachado muitas vezes de populista, Victor Hugo encontrou uma ressonância enorme - os franceses, em geral o consideram seu maior poeta, no que vários críticos não concordam, acusando-o de ter mais posição do que uma presença ativa. Seria um homem de paz e ideias num mundo infernal de guerras, assim Victor Hugo declara sua esperança na força dos ideais - mesmo chamados de ingênuos ou utópicos. Mas a utopia não é ingênua? Mas não importam as posições contrárias, visto que o seu Os miseráveis - como já previa Carpeaux - teve mais de cinquenta adaptações para o cinema, televisão, história em quadrinhos e uma ópera, ou melhor, um musical.

Impossível fazer aqui um resumo ou uma paráfrase de um livro que contém quase duas mil páginas e centenas de personagens. O que se quer com este texto é demonstrar que a multidão e suas personagens - o protagonista e os coadjuvantes, se é que podemos tratá-los assim -, escondem-se através de nomes que se modificam conforme a necessidade de sobrevivência. Além disso, é notório que o universo literário de um homem não marxista, mas humanista e revolucionário por excelência, possibilita um cruzamento entre sua criação literária do século XIX e as adaptações audiovisuais dos séculos XX e XXI. Mostrando que, possivelmente, o século XIX não tem grandes diferenças estruturais nem humanísticas comparadas ao século atual.

A história de Jean Valjean foi iniciada em 1845, escrita durante quinze anos e publicada em 1862. Aos 25 anos, Jean rouba um pão para alimentar os filhos de sua irmã. É preso, condenado a cinco anos e se transforma no prisioneiro 24.601, como trabalhador nas galés. Por várias tentativas de fugas, sua pena se transforma em 25 anos. Logo, vê-se que Victor Hugo coloca um homem dividido em duas metades de vida - uma livre, como Jean, outra presa, como um número. 
Além disso, o próprio nome real da personagem "Jean Valjean" é dividido em dois, espelhando-se. As três letras de ligação, "Val" parecem ser o percurso que fará durante toda a obra, atravessando a França, pois todo "vale" é um terreno baixo e mais ou menos plano, à margem de um rio, cercado por montes ou montanhas. A representação destas palavras - o nome Jean Valjean é, portanto o início e o fim do caminho da personagem principal.

Na obra em si, Victor Hugo, ao apresentar sua personagem, diz que Jean era irmão de Jeanne, filho de Jeanne Mathieu e de "Jean Valjean ou Vlajean, provavelmente alcunha de voilá Jean" (HUGO, 2012, p. 143). Mãe, pai, irmã e filho com o mesmo nome e com a possibilidade de o sobrenome ser uma corruptela que significa "eis ali, ali está", pode demonstrar que não havia sobrenome, apenas um cumprimento banal para pessoas ordinárias. Nada mais simples e rez-de-chausseé.

Ao ser libertado, dezenove anos depois de sua prisão, em uma espécie de condicional, recebe um passaporte amarelo, no qual está carimbado que é um ex-condenado, o que Ihe impossibilita acolhimento em hospedagens e afins. Como tem sempre que mostrar seus documentos, sua permanência em nenhum lugar é aceita e a possibilidade de ser pago decentemente por um trabalho é impossível. Já não é mais um cidadão, e sim um pária com um documento que paradoxalmente Ihe nega qualquer direito.

Em Digne, a 830 quilômetros de Paris, é acolhido pelo bispo local, dom Bienvenu, depois de ser escorraçado de vários lugares. Homem adorado por seus fiéis, recebe Jean e Ihe dá comida em talheres de prata, bebida e uma cama confortável, fazendo jus ao seu nome, "Bem Vindo". Recebe-o com carinho e sem medo. Mas Jean, durante a noite rouba a prataria e foge, sendo imediatamente preso. Para seu espanto, dom Bienvenu o recebe calorosamente e mente aos guardas, dizendo que havia Ihe dado a prataria. Faz mais, dá-lhe os castiçais de prata da casa, que valem duzentos francos. Com isto, o bispo diz a Jean: "Jean Valjean, meu irmão, o senhor não pertence mais ao mal, mas ao bem. Resgatei a sua alma; liberto-a dos pensamentos sinistros e do espírito da perdição, e entrego-a a Deus" (HUGO, 2012, p. 173). 
Em Montreuil-sur-Mer nasceu Fantine. Sem sobrenome, apenas Fantine, nome que lhe foi dado por um transeunte que a encontrou pelas ruas. É visível o descaso com que a sociedade da época trata quem não tem laços - apenas um nome, apenas uma figura entre a multidão. Fantine trabalhou, sobreviveu, mudou-se para Paris, onde se apaixonou, engravidou e foi abandonada.

A espiral da queda de Fantine é relatada de uma forma totalmente dramática, no entanto sua transformação em prostituta não tem palavras condenatórias. A sucessão de tragédias é narrada de forma a mostrar que não havia outra saída. Depois de ter deixado ingenuamente sua filha Cosette - cujo nome verdadeiro é Eufrásia, mas chamada também de Cotovia - com o casal Thérnadier, dupla de taberneiros e ladrões a troco de uma quantia mensal, Fantine volta a Montreuilsur-Mer. Vai trabalhar na fábrica de miçangas do senhor Madeleine.

Aí está de novo Valjean, agora como empresário milionário, graças aos progressos da indústria daquela época. Em poucos anos sua empresa prosperou de tal forma que a cidade se transformou em polo comercial.

Sob o nome Madeleine vemos, portanto um homem que se acha um pecador arrependido e que se esconde atrás da personagem bíblica. E com este nome ele faz uma gestão pacífica de empresário e torna-se Maire da cidade - administrador local, espécie de prefeito -, depois de ter recusado esta honraria dada pelo rei, duas vezes. "Essa foi a terceira fase de sua ascensão. Madeleine tornara-se o senhor Madeleine, e o senhor Madeleine transformara-se em Maire" (HUGO, 2012, p. 258). Terceira fase de sua ascensão, mas a quinta fase de sua vida: Jean Valjean, prisioneiro 24.601, Madeleine, senhor Madeleine, Maire. Nota-se que a pronúncia de Maire é a mesma de mãe, mère, na língua francesa. Ele é a "mãe" da cidade.

Os anos se passam e Fantine, operária, manda mensalmente dinheiro aos Thérnadier, que a exploram pedindo cada vez mais e tratam Cosette como escrava. Na fábrica, descobrem que é mãe solteira, sendo demitida. Sem dinheiro, sem casa, vende os cabelos, os dentes, se torna uma prostituta de rua. Definha de tristeza e subnutrição quando é presa, injustamente, pelo inspetor da cidade: Javert. 
Victor Hugo caracteriza o policial como o mal travestido em homem, principalmente quando o descreve fisicamente, no entanto o traduz como a lei em seu estado mais simples e bruto. A moral de Javert não é pessoal, não é algo que tenha sido desenvolvida pela reflexão ou contemplação. É a moral dos regulamentos, ele é rude e rígido. Tem uma vida simples e não tem problemas morais, tudo está apresentado a ele em números e parágrafos. Nascido em uma prisão é filho de uma cartomante cujo marido estava nas galés.

Crescendo, julgou-se excluído da sociedade e perdeu toda a esperança de nela entrar. Notou, igualmente, que a sociedade mantém irremissivelmente afastadas duas classes de homens; os que a atacam e os que a protegem; ele só podia escolher entre essas duas classes, ao mesmo tempo que sentia em seu íntimo não sei que rigidez, regularidade ou probidade, de mistura a um ódio inexprimível a essa classe de boêmios a que ele pertencia. Entrou para a polícia. Deu-se bem. Com quarenta anos, fora nomeado inspetor (HUGO, 2012, p. 267).

Assim, uma nova personagem nos é apresentada, filha das mesmas ruas francesas do século XIX, inspirado em Vidoq - chefe da polícia napoleônica e produto das classes miseráveis. Essa personagem é a antítese de Valjean: "Ninguém deixará de notar que Hugo pretendeu forjar o parentesco entre o homem da lei e o fora da lei - estas duas classes de homens que a sociedade mantém irremediavelmente fora de seus limites -, pela simetria inversa dos fonemas" (VJ e JV) (LANOT et al, 2002, p. 239).

Ao ver a prisão de Fantine, Madeleine resgata-a e a leva ao hospital da cidade. Ali conhece sua história, descobre que a moça era uma de suas operárias, e se sente na obrigação de ajudá-la. Promete à moribunda Fantine que Ihe trará Cosette.

Mas há mais miséria humana. Javert há tempos desconfiava do Maire e tem sua certeza confirmada quando o vê levantar com os ombros uma carroça para socorrer Fauchelevent, um morador da cidade. Relembra que havia visto um preso fazer algo semelhante: Jean Valjean. Denuncia-o às autoridades. Em outra cidade um homem é preso como se fosse Valjean, o que deixa Javert 
desesperado pelo erro que imaginava ter cometido e relata ao Maire, pedindo perdão. Vemos, portanto uma tragédia de erros que tem de ser resolvida.

Valjean agora sabe que há alguém preso confundido com ele. Testemunhas dizem que aquele é Jean Valjean. O que fazer? Resolve ir até à cidade onde o inocente está sendo julgado e se entrega. Diz a uma plateia perplexa onde pode ser encontrado e volta apressadamente à Montreuil-sur-Mer para ver Fantine. Ao chegar, testemunha a morte da moça enquanto Javert o prende. Consegue se libertar, enterrar algum dinheiro, mas alguns meses depois, quando tenta ir em busca de Cosette, é novamente preso e se torna o número 9.430. No entanto, a sorte ainda existia. Alguns meses depois o jornal de Toulon publica o seguinte relato:

17 de novembro de 1823. Ontem, um forçado, cumprindo pena a bordo do Orion, depois de socorrer um marinheiro, caiu no mar e se afogou. Não foi possível encontrar-lhe o cadáver. Presume-se que tenha ficado preso nas estacas da ponte do Arsenal. Estava registrado sob o número 9430; chamava-se Jean Valjean (HUGO, 2012, p. 258).

Valjean cumpre sua promessa e resgata Cosette. Os Thérnadier a vendem para pagar dívidas. O casal de escroques, inclusive, tem cinco filhos, mas apenas as duas meninas mais velhas Ihe são caras, o terceiro filho é Gavroche - típica criança de rua, que vive por si só, e dois menores que são "alugados".

Thérnadier, além de taberneiro é um trapaceiro e com a falência de seu estabelecimento se transforma em membro de um bando de ladrões. Dependendo de cada golpe ou situação, ele é conhecido por um nome. Jondrette, quando se muda para Paris e se torna membro de um bando de ladrões, é o "rei dos esgotos parisienses"; senhor Fabantou, poeta Genflot, Don Alvarez, dona Balizard, quando assina cartas pedindo auxílio e usa suas filhas e esposa para extorquir cidadãos e Senhor Thenárd, falso nobre. Thérnadier, portanto se esconde sempre atrás de um nome dependendo da situação.

Interesseiro, fraudulento, acompanhado de uma mulher monstruosa, ele martiriza Cosette, que vende como um objeto a Valjean. Tornado-se chefe de um bando de criminosos, ele assume o reinado dos esgotos: é o símbolo do povo desencaminhado, conduzido à ignomínia. Seu nome se torna sinônimo de baixeza (LANOT et al., 2002, p. 239). 
Com Cosette resgatada, uma nova vida se inicia, mas sempre com Javert a seu encalço - o inspetor não crê na morte do prisioneiro 9.430. E em uma perseguição "cinematográfica" Jean e Cosette se escondem nos jardins de um convento, no qual o jardineiro era Fauchelevent, aquele homem que anos atrás havia ajudado ao levantar a carroça onde estava preso. E com um novo nome Jean se batiza: Ultime Fauchelevent, irmão do jardineiro. Por causa desse falso nome e parentesco consegue um emprego, e uma vida educacional para Cosette no convento.

A vida prossegue, Jean Valjean e Cosette alugam uma casa em Paris. Ele agora é o respeitado senhor Leblanc. ("O branco", o sem passado). Cosette se apaixona por Marius, um jovem romântico, advogado e revolucionário. Em dívida com o pai morto, acredita que Thérnadier o salvou em Waterloo. Republicano, faz parte de um grupo de estudantes sonhadores, que revivem o ideal de 1789, que querem salvar da servidão o povo sempre humilhado. Seu grupo é conhecido como os estudantes do ABC, amigos da alfabetização. Acidentalmente, Marius faz a ponte entre dois miseráveis: Valjean e Thérnadier.

Marius é também amigo do garoto Gavroche, pivete parisiense, representante da cultura popular, herói sacrificado nas barricadas, tendo na descrição de sua morte várias referências a Cristo. Sua imagem faz parte do imaginário coletivo e tornou-se, na França, um substantivo comum. Paris, no entanto está em chamas. Os estudantes e a população mais pobre se revoltam com os descalabros do governo que se distanciou dos ideais da Revolução Francesa. Javert se apresenta como um partidário, mas é desmascarado por Gavroche e salvo por Jean Valjean, então senhor Leblanc.

Em uma das investidas policiais sobre as barricadas feitas pelos revolucionários, Gavroche é assassinado e Marius, ferido, é salvo pelo senhor Leblanc. Atravessando os esgotos de Paris, onde a imundície predomina, Valjean leva o corpo do rapaz desmaiado até à saída. Ali se encontra novamente com Javert que o ajuda a levar Marius até a casa do avô e deixa livre Valjean. Pela primeira vez, Javert está em uma situação na qual ele desrespeita a lei. Seu conflito interior leva-o ao suicídio, saltando para o rio Sena. 
Marius não sabe quem o salvou, e aos poucos se restabelece, recebendo sempre a visita de Cosette, levada pelo pai. Casam-se e Jean Valjean, agora apenas senhor Jean, relata a Marius sua história e pede-Ihe para não contar nada à esposa. Esconde-se em um quarto de sua velha casa e vai definhandose. Cosette nada sabe.

Thérnadier procura Marius e querendo extorqui-lo, relata a história de Jean - a qual Marius já conhece, e acusa-o de ter matado um jovem e o carregado sobre os ombros por todo o esgoto de Paris. Marius, perplexo, vê quem foi seu salvador e agitado leva Cosette até Jean. Pede-lhe perdão por ter acreditado que ele era apenas um pária. Jean morre nos braços do casal. Enterrado no Père-Lachaise tem sobre seu túmulo apenas uma pedra sem nenhum nome incrustado. Segundo Coli,

\footnotetext{
Victor Hugo, em Os miseráveis, estabelece a dupla/perseguido perseguidor, policial/bandido, em que este último passa de identidade em identidade. Ao mesmo tempo, Os miseráveis distingue culpa legal, jurídica e inocência de fato, demonstrando um conflito entre regras coletivas e história individual, que termina por assinalar o caráter desumano e fatídico de uma sociedade racional em seus processos de controle (COLI, 2010, p. 251).
}

Vê-se, portanto a espiral de um homem, que entra na prisão como primário e sai um pária embrutecido. Para se libertar de tal estigma muda constantemente de identidade e profissão: Jean Valjean (curiosamente um nome espelhado), prisioneiro 24.601, monsieur Madeleine (nome baseado na pecadora arrependida), prisioneiro 9.430, Ultime Fauchelevent, senhor Leblanc, senhor Jean. Mistura-se na multidão e no anonimato nominado para conseguir a redenção e auxiliar o próximo.

Este drama, escrito de forma comovente, cheio de intertextos, fragmentos da história da França do século XIX e opiniões humanistas, inspirou várias versões - de história em quadrinhos a inúmeras versões fílmicas. As primeiras adaptações remontam ao cinema mudo: em 1897, foi feita uma versão pelos Irmãos Lumière, e em 1907, uma parte da história se tornou filme pelas mãos 
de Alice Guy Blaché, a pioneira cineasta. E se em 1935, Richard Boleslawski, mostrou uma versão sombria e realista, em 1995, Claude Lelouch trouxe a adaptação para história do século XX. Como arte sequencial, em 2010, o roteirista francês Daniel Bardet, criou quadrinhos magníficos traduzidos para o português pela editora L\&PM, resumindo a história de Jean Valjean, sem perder as características originais.

A última adaptação, de 2012, com direção de Tom Hooper - ganhador do Oscar de 2011 de melhor diretor por O discurso do rei -, e produção britânica, tem por base o musical de Claude-Michel Schönberg, com libreto de Alain Boublil e letras de Herbert Kretzmer, originado do teatro francês em 1980. Foi exibida em 42 países e 21 idiomas, já tendo sido conferido por mais de 60 milhões de pessoas. Em 2014 completa 30 anos em cartaz.

Por ser uma versão cinematográfica do teatro lírico, e não da obra em si, há peculiaridades que encantam a quem ama um musical, e são odiadas por quem prefere um western e acha que a noviça rebelde nunca deveria ter se casado. Todo o filme foi rodado com os atores cantando ao representarem, sem dublagem no estúdio. Não há nenhum texto falado. Ao comentarmos essa versão veremos que ela tem a força da emoção lírica. É aí que está seu ponto forte. Fantine, representada por Anne Hathaway, faz a plateia ir ao pranto com a interpretação de "I dreamed a dream", depois de ter seus cabelos cortados à faca e seus dentes arrancados. Por essa cena, que traduz a degeneração de sua personagem, ganhou o Oscar de melhor atriz coadjuvante de 2013.

O roteirista William Nicholson, com a colaboração dos autores da adaptação para o teatro, estruturou uma narrativa linear na qual Tom Hooper estabeleceu as imagens através de diversas artes - na tela, expressam o teatro, a ópera, a fotografia, a música, a pintura, a dança. Cinema e musical se mesclam em harmonia com a realidade - é a História se desenvolvendo na tela.

Logo, parece-nos apropriado constatar que incidentalmente o manifesto de Victor Hugo, do qual tratamos no início deste artigo, se completa nesta adaptação 
cinematográfica e musical: o lirismo dos tempos primitivos; os poemas épicos dos tempos antigos e o drama dos tempos modernos.

E se Os miseráveis é uma obra do século XIX, veremos que ainda hoje é ecoada nas personagens do século XXI, mulheres e homens trabalhadores que têm ceifadas suas vidas por causa de crimes primários e se escondem através de novas identidades na multidão, nas ruelas ordinárias de qualquer cidade grande ou nos rincões do "Brasil Profundo" e quiçá do mundo. 


\section{Referências}

CARPEAUX, O. M. História da literatura ocidental. Vol. III. São Paulo: Leya, 2012.

COLI, J. O corpo da liberdade: reflexões sobre a pintura do século XIX. São Paulo: Cosac Naify, 2010.

BARDET, D. Os miseráveis de Victor Hugo. Porto Alegre: L\&PM, 2012.

HUGO, V. Do grotesco e do sublime. São Paulo: Perspectiva, 2007.

HUGO, V. Os miseráveis. São Paulo: Cosac Naify, 2012.

LANOT, F. et al. Dicionário de cultura literária: 100 citações e 100 personagens célebres. Rio de Janeiro: Difel, 2007.

\section{Referências audiovisuais}

Os miseráveis. Filme dirigido por Richard Boleslawski, Estados Unidos, 1935.

Os miseráveis. Filme dirigido por Claude Lelouch, França, 1995.

Os miseráveis. Minissérie da TV francesa dirigida por Josée Dayan e coproduzida por Gérard Depardieu, 2000.

Os miseráveis. Adaptação britânica baseada no musical de Alain Boublil e ClaudeMichel Schöenberg, dirigido por Tom Hopper, 2012. 